\title{
Beta adrenoceptor antagonists after myocardial infarction-where are we now?
}

\author{
D A CHAMBERLAIN
}

From Royal Sussex County Hospital, Brighton

We have reached a milestone in our attempts to achieve secondary prevention after myocardial infarction. At last the evidence is compelling ${ }^{12}$ that a group of drugs can reduce mortality as a result of long term administration during the convalescent phase and afterwards.

Timolol, ${ }^{3}$ metoprolol, ${ }^{4}$ propranolol, ${ }^{5}$ and sotalol ${ }^{6}$ have recently been subjected to well conducted randomised clinical trials with designs which have taken account of lessons learnt from earlier studies. ${ }^{7}$ Mortality within the treated groups has been reduced by $18^{6}$ to $36 \%{ }^{3}$; the reduction achieved conventional levels of significance in three of these trials. ${ }^{3-5}$ An additional trial with propranolol ${ }^{8}$ showed a significant reduction in sudden death (prospectively chosen as the endpoint) in the survivors of acute myocardial infarction who were followed up for 12 months.

These beta adrenoceptor antagonists have diverse ancillary properties. For example, of the four agents only metoprolol has so-called cardioselectivity in that it affects principally beta ${ }_{1}$ receptors, only sotalol has class III antiarrhythmic activity (prolongation of the action potential), and only propranolol has appreciable membrane stabilising activity at high plasma levels. Timolol has none of these properties. It seems likely that the benefit has been conferred by blockade of the sympathetic innervation of the heart, little influenced by ancillary properties unique to the drugs in question. While no single trial can readily provide evidence strong enough universally to influence management of the most important illness of our time, collectively they leave little room for doubt. Physicians must now reappraise whether or not prophylaxis with beta adrenoceptor antagonists should be widely recommended for patients who have survived the initial phase of infarction.

Not all trials of secondary prevention with beta adrenoceptor antagonists have suggested a protective effect: the clear trend has emerged particularly among the larger recent studies in which treatment began in the later stages of the acute illness. A convenient and informative way of comparing the results of the published trials to obtain a balanced view of the results was designed by Baber and Lewis'; it will no doubt find wide application in reviews of other contentious topics. ${ }^{10}$ Following their scheme, Fig. 1 shows the results of the important secondary prevention trials $^{356811^{-14}}$ in which treatment with placebo or beta adrenoceptor antagonists was started four to 14 days after infarction. These studies were also characterised by being large enough to have more than 20 deaths recorded, having acceptable randomisation, and availability of results on an intention-to-treat basis. ${ }^{15}$ Each bar represents one trial, identified by the drug which was used and by the first author or groupidentification of the report. The tall vertical division extending from the baseline separates overall benefit (to the right) from overall adverse effect (to the left). The small vertical line within each bar shows the mean effect obtained within each trial using the stringent intention-to-treat method of analysis. The width of the bars indicates $95 \%$ confidence limits: thus, the more convincing the result the smaller the bar. Only bars lying totally to one side of the division provided results that achieved conventional levels of significance, but the favourable trend is reinforced by most trials. The tail to the left of each bar can be longer than the tail to the right for statistical reasons reflected in the baseline: a reduction in mortality of more than $100 \%$ is impossible, but an increase in mortality of more than $100 \%$ is a possible outcome.

The majority who now accept the evidence of these trials will still want to know the answers to several remaining questions. How do beta adrenoceptor antagonists work in this context? If treatment is indicated when should it be started and for how long should it be continued? Does it matter which drug is used and in what dose? Finally, and most important, should all patients without contraindications to beta blockade be treated? Unfortunately complete answers 


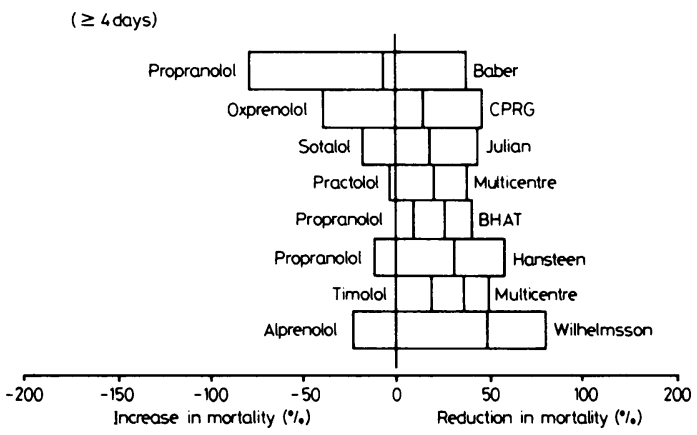

Fig. 1 The major late entry trials of secondary prevention after myocardial infarction using beta adrenoceptor antagonists. The full explanation is in the text. (The figure was kindly provided by $f$ A Lewis. See references 9 and 15.)

to these questions are not currently available. Judgements must be made on incomplete evidence, and for a time at least practice with regard to the use of beta adrenoceptor antagonists may continue to vary between centres.

\section{How do beta adrenoceptor antagonists confer protection?}

The manner in which beta adrenoceptor antagonists confer long term protection for patients after myocardial infarction remains speculative. Perhaps we should be surprised that any single drug can be shown convincingly to be efficacious in secondary prevention after myocardial infarction, since two particular problems combine to pose a daunting challenge to the trialist. The first is the relatively low mortality in the convalescent phase and the second the disparate mechanisms of death which have to be countered.

The total first year mortality in the placebo group of major trials has not exceeded $15 \%$ except in a Copenhagen alprenolol study ${ }^{16}$ (which showed anomalous results in an older subgroup). While the low mortality reflects in part the caution of physicians who entered patients into trials, most deaths inevitably occur before secondary prevention can be initiated. Regarding the disparate mechanisms of death, the several distinct factors concern the electrical stability of the heart, the extent of existing myocardial necrosis, and the severity of obstructive coronary artery disease threatening viable and functioning myocardium. Thus, some patients die as an indirect result of old events while others die from new complications of their underlying disease. Could a drug which influences only one factor-the occurrence of lethal arrhythmias for example-reduce overall mortality by so conspicuous a margin as $26 \%$, which is the average reduction achieved in the major late entry trials? This seems unlikely and we must entertain at least a suspi- $\stackrel{\vec{c}}{.}$ cion that more than one mechanism is operative.

The actions of beta adrenoceptor blocking agents are complex and may influence the heart directly and indirectly. Arrhythmias that are potentially lethal are more likely to occur under conditions of heightened sympathetic drive and thus may be reduced by effective blockade. Though the prevalence of non-fatal ventricular arrhythmias in the early weeks after myocardial infarction may not be reduced overall by beta receptor antagonists, ${ }^{17}$ those that are clinically apparent often do respond to treatment, ${ }^{18}$ and the threshold for the experimental induction of ventricular fibrillation is raised by these drugs. ${ }^{19} 20$ The possibility of protection against a sudden arrhythmic death must be strong. Moreover, indirect evidence suggests that the balance between the supply of nutrients to the myocardium and its metabolic requirement is improved by beta adrenoceptor antagonists. ${ }^{21}$ Some have postulated that an adverse balance maintained long enough to cause myocardial damage, particularly when induced by sympathetic stimulation, may initiate the process which leads to infarction even in the absence of fresh coronary occlusion as the primary event. ${ }^{22}$ If this be the case, prognosis may be improved by the same mechanisms as those that confer on the drugs their antianginal properties. Beta adrenoceptor antagonists have other actions to a varying degree, which may influence favourably the prognosis of arterial disease or reduce the tendency for new thrombus formation. Thus, with at least some agents platelet aggregation is lessened, ${ }^{23}$ thromboxane synthesis is influenced, ${ }^{24}$ blood pressure is lowered, renin production is reduced, ${ }^{25}$ and altered lipolysis modifies myocardial metabolism ${ }^{26}$ in an oxygensparing manner.

Protective mechanisms influencing the results of the trials may be reflected in a disparity between different types of new events in the placebo and treated groups. Before considering the altered proportions of $\delta$ those with sudden death on the one hand and reinfarction on the other, two important points should be $ᄋ$ made. First, the mode of death is not easy to determine in patients who die outside hospital, and the problems of categorisation are compounded in multicentre trials. Secondly, death and reinfarction are 0 not independent. Some of those who die suddenly do $\tilde{O}$ so as a result of reinfarction. If a drug protects against arrhythmic death in patients potentially in this group $\bar{O}$ it would be expected to increase the proportion having 0 non-fatal reinfarction, the increase representing those $\stackrel{D}{\mathbb{D}}$ who have been protected from early ventricular fibril- $\stackrel{\rho}{?}$ lation. In fact, the major trials show not only a reduc- $\square$ tion in sudden death but usually an additional reduc- $\stackrel{O}{\circ}$

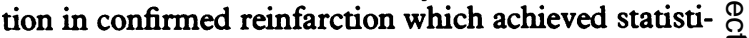
cal significance in $\operatorname{two}^{36}$ of them. The trend which is $\mathbb{D}$ 
against that which would be expected from an antiarrhythmic effect alone suggests that beta adrenoceptor antagonists are likely to confer benefit both by reducing the chances of sudden death and by influencing favourably the risks of reinfarction.

\section{When should treatment be started?}

The optimum interval between infarction and the start of treatment with beta adrenoceptor antagonists may become clearer when the results of important current studies are available. The issues are complex. Most mortality after infarction occurs early; moreover the full extent of myocardial necrosis can at this stage be influenced by drugs which spare myocardial metabolic demands. Thus, drugs have most opportunity to influence both immediate outcome and late prognosis when administered early. But powerful arguments-some based on fact and others on hypothesis-can be adduced for delaying the initiation of beta blockade. Immediately after infarction patients are most vulnerable to possible adverse effects from reduced contractility and depression of sinus and atrioventricular nodal function. Moreover infarction is probably attended or even caused by functional coronary constriction ${ }^{27} 28$; the beta receptors of the coronary arteries are dilator, ${ }^{29}$ and their blockade may leave unopposed the additional constrictor effect ${ }^{30}$ mediated by sympathetic influences working through unblocked alpha receptors. Thus with early intervention there is more to lose and more to gain. The balance of benefit and harm may well change more than once through the early hours and first days of infarction, may differ between patients, and may depend critically upon patient selection. For the moment we can depend only upon the evidence we have from relatively early intervention studies with end results based upon mortality. Those in which administration began within three days of the onset of symptoms are represented in Fig. 241631-37 which makes use of the same design as Fig. 1 for later intervention trials. Only the Swedish metoprolol study, in which treatment began after a mean delay of 11.3 hours, shows a clear-cut positive result. Even here, the data suggest that the benefit occurred after the first 10 days of treatment. Thus, no trend towards benefit emerges in early intervention studies which have mortality as an end point. A trial of intravenous atenolol ${ }^{38}$ in patients with suspected myocardial infarction has, however, suggested that infarct size may be limited. The drug seems capable of relieving pain in the acute stage of infarction, ${ }^{39}$ which also suggests a favourable effect, but data are awaited on a more extensive early entry study relating to prognosis.

Early intervention trials have inherent design difficulties. Diagnosis at the outset of chest pain can-

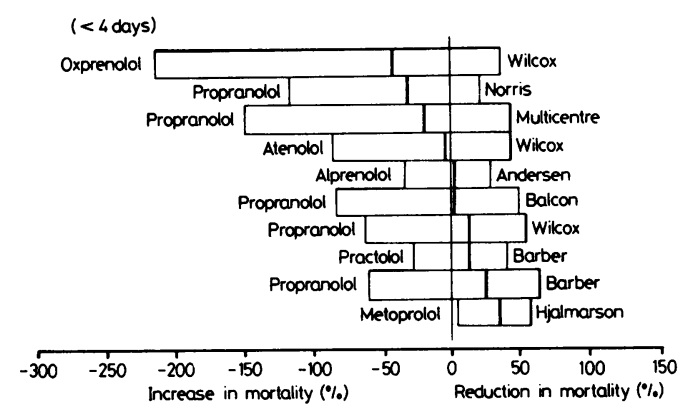

Fig. 2 The major early entry trials of secondary prevention after myocardial infarction using beta adrenoceptor antagonists. The full explanation is in the text. (The figure was kindly provided by $\mathcal{F} A$ Lewis. See references 9 and 15.)

not always be established reliably, and the numbers truly at high risk are diluted by patients known in retrospect to have coronary insufficiency or even non-cardiac pain-which carry little or no early mortality. Even contraindications to beta blockade may be less apparent at this stage. We must conclude for the moment that the case for early intervention has not been made. If treatment for secondary prevention by beta adrenoceptor agents is to be given, the drugs should on present evidence be started a few days after infarction unless special reasons exist for earlier intervention.

\section{How long should treatment be continued?}

Advice is more difficult to provide on the vexed question of when treatment should reasonably be stopped in those for whom secondary prevention is appropriate. We know only that the mortality curves for patients on placebo and those on active treatment in most recent trials move apart for at least six months and sometimes for 12 to 18 months ${ }^{56}$ before tending to run parallel. Separation of the curves seemed to continue even longer in the timolol trial. ${ }^{3}$ What can we conclude? Only that prophylaxis should be continued for a minimum of six months; in practice, most physicians will want to maintain the tablet regimen for longer-three years or more-if this be practicable and the patient is not inconvenienced by obtrusive unwanted effects. It must be stressed that mortality curves which run parallel do not indicate absence of maintained benefit; this would be signalled by early convergence of curves while medication continued. The crucial test has not been made. Further randomisation of the group on active treatment at some time when the value of intervention had been shown could be used to show either that the trend for the new placebo subgroup deviates unfavourably from those still on beta blockade (that is treatment would better have been continued) or that the new division made 
no detectable difference (that is all treatment could reasonably have stopped). Theoretically this way of terminating a trial with a positive outcome is attractive, but the logistics would be daunting both because numbers enrolled would have to be very large and because interpretation would be confused by "dropins"-patients who would not tolerate cessation of treatment on symptomatic grounds. Probably we will never have better evidence than that already available to us, so that clinical judgement will remain untrammelled by demonstrable facts.

\section{Which drugs are appropriate for secondary prevention?}

The cautious physician, anxious to ensure that his patients share the benefits demonstrated by the trials, will imitate exactly one of the prescriptions shown to be successful in secondary prevention. The case for sotolol and alprenolol is suggestive but not unassailable, the oxprenolol trials so far offer little support for a protective effect, and no trials have been reported for several other beta adrenoceptor antagonists. He will turn, therefore, to the use of timolol $10 \mathrm{mg}$ twice daily, metoprolol $100 \mathrm{mg}$ twice daily, or propranolol in a dose ranging from $180 \mathrm{mg}$ to $240 \mathrm{mg}$ daily. The optimum dosage of beta adrenoceptor antagonists is, however, rarely a matter for critical adjustment despite vagaries of first pass metabolism influencing blood levels of some ${ }^{40}$ and unusually slow metabolic oxidation that can affect others. ${ }^{41}$ It seems likely that conventional blocking doses of all the available drugs in this class share-at least to a degree-the protective value shown for some of them. But the possibility remains that some confer greater protection than others for reasons that have not at present been defined. All manufacturers of beta adrenoceptor antagonists will be anxious to have trials demonstrating the benefits of their own product. Unfortunately for the cause of therapeutic justice most physicians will now feel that the time for long term trials of active beta blockers against placebo in the convalescent phase of infarction has passed. A placebo group may be unethical, and comparative trials would require numbers that are unrealistic. On the questions of which drug and in what dosage, we have very nearly all the information which will ever be forthcoming unless new data emerge on mechanisms of action which are not shared equally by the available agents in this class.

\section{Should all patients without contraindications be treated?}

Though secondary prevention with beta adrenoceptor antagonists has been demonstrably effective under the conditions of the best trials, their value in routine clinical practice has not yet been clearly defined. To do so is of crucial importance. Those most closely on involved in trials understand best what blunt instruments they usually are, and perhaps few are so blunt as those with beta blockers. The problems are manifold.

First we must consider their unwanted effects. Many patients cannot tolerate beta blockade because of impaired myocardial function, conduction disorders, asthma, and-less importantly-peripheral vascular disease and insulin dependent diabetes. Not all the trials gave adequate details of the proportion of patients excluded or withdrawn because of contraindications, but approximately $30 \%$ have been consi- i dered unsuitable for treatment. With more wide- $\vec{P}$ spread and less skilled use of beta receptor antagonists or in secondary prevention some patients will be treated 음 inappropriately. The risks of widespread use of the drugs in angina have been proved small, but patients $T$ are more vulnerable after infarction. The balance of $\frac{\bar{O}}{7}$ risk against benefit may tilt enough to lessen the overall favourable impact of therapy when treatment is $₹$ initiated more frequently without the benefits of skil- $\vec{\varphi}$ led clinical observation, good quality radiology, and $\stackrel{\infty}{\omega}$ electrocardiography. Even those on treatment appropriately will suffer side effects that may have an important impact on the quality of life. ${ }^{42} \mathrm{We}$ must be sure that the advantages are commensurate, particularly when we learn from the timolol trial that on $\mathbb{D}$ average every life saved (that is death postponed) $\stackrel{2}{\Rightarrow}$ necessitated approximately 24 patient-years of treatment. ${ }^{43}$ The position is different in the presence of angina, for drugs that relieve an unpleasant symptom may be acceptable even if they cause side effects; but in symptomless patients after infarction the problems $\overrightarrow{\overparen{D}}$ are similar to those in hypertension where compliance is a well recognised problem.

The frequency with which angina complicates the post-infarction phase must not be overlooked, and $\delta$ indeed may have exaggerated the apparent role of beta

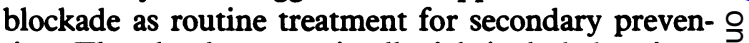
tion. The placebo group in all trials included patients with angina: all reasonable efforts will have been made to keep them in the trial by the liberal use of $\mathrm{N}$ glyceryl trinitrate, save when the symptoms were o severe enough to justify withdrawal. But the presence $\tilde{O}$ of angina is a marker of risk. Accepting now that beta $\underset{\omega}{N}$ blockade does reduce mortality, and accepting that in ordinary clinical practice those relatively high risk ${ }_{0}$ placebo patients with angina would have received beta $\frac{\sim}{\Phi}$ adrenoceptor antagonists on symptomatic grounds, we $\stackrel{?}{+}$ may suspect, in retrospect, that the trial conditions $\square$ increased slightly the overall mortality in the placebo $\stackrel{\circ}{\circ}$

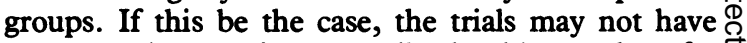
answered the question we really should pose: how far $\stackrel{\mathbb{Q}}{\mathscr{Q}}$ 
does beta blockade reduce mortality in those patients after infarction who do not have an existing indication for treatment? We have no satisfactory way of obtaining this information.

Unfortunately angina is not the best marker of risk. But many now believe that effort testing in the convalescent phase after infarction can be used to identify patients threatened by serious obstructive lesions of the coronary arterial supply of functioning myocardium, and that in this group will be found most of those destined to die within the ensuing year or so. The criteria used to identify risk have varied and have been based upon variables such as the occurrence of angina or an inadequate blood pressure response to exercise, ${ }^{44}$ the prevalence of ventricular arrhythmias, ${ }^{45}$ initial chest $x$-ray appearances, ${ }^{46}$ ejection fraction, ${ }^{47}$ and ST segment depression during effort tests. ${ }^{4448}$ Therroux and his colleagues ${ }^{48}$ obtained a very clear cut result with the relatively simple technique of selecting patients based upon new ischaemic changes occurring in lead V5 of the exercise electrocardiogram. The majority of patients, $66 \%$ of the total, showed no fresh changes and had a one year mortality of $2 \%$. The remainder with fresh changes had a mortality more than 10 times higher. If it be true that an identifiable majority of patients after infarction have a very low mortality subsequently, then this majority of patients requires no drug treatment at all for secondary prevention. We must refine our techniques for identifying long term risk as a matter of urgency. Even then the role of beta adrenoceptor antagonists requires further definition, for surgery too may be shown to alleviate risk after infarction as it undoubtedly can for selected patients with angina. ${ }^{49}$

\section{Some conclusions}

Where are we now? We have reached our milestone and we must select carefully the best way ahead. Many important questions will remain forever unanswered, but our main objectives should be clear. After myocardial infarction, patients with angina and other existing indications for beta adrenoceptor antagonists should be identified and treated with renewed enthusiasm. We should learn to screen the remaining patients for evidence of high risk using methods which offer the best compromise between simplicity and predictive accuracy, and treat these by whatever means is most appropriate. For the present and in the absence of contraindications the beta blockers have no serious contenders for medical management. Many patients, however, do not require the burden of maintenance drug treatment.

My thoughts about beta blockade for the secondary prevention of myocardial infarction have evolved largely as a result of discussions with colleagues whose views have often been more perceptive than mine. They include Professor Desmond Julian, Dr Richard Vincent, Professor John Hampton, Dr Nigel Baber, Professor Geoffrey Rose, and Mr John Lewis. Any useful concepts are likely to be theirs, and any errors are surely mine.

\section{References}

1 Hampton JR, Breckenridge A, Rose G. Should every survivor of a heart attack be given a beta-blocker? Part I Evidence from clinical trials. Part II Evidence from a clinical pharmacological standpoint. Part III Some conclusions. Br Med F 1982; 285: 33-40.

2 Anonymous. Long-term and short-term beta-blockade after myocardial infarction [Editorial]. Lancet 1982; i: $1159-61$.

3 The Norwegian Multicenter Study Group. Timololinduced reduction in mortality and reinfarction in patients surviving acute myocardial infarction. $N$ Engl f Med 1981; 304: 801-7.

4 Hjalmarson A, Elmfeldt D, Herlitz J, et al. Effect on mortality of metoprolol in acute myocardial infarction. A double-blind randomised trial. Lancet 1981; ii: 823-7.

$5 \beta$-Blocker Heart Attack Trial Research Group. A randomised trial of propranolol in patients with acute myocardial infarction I. Mortality results. $\mathcal{F A M A} 1982$; 247: 1707-14.

6 Julian DG, Prescott RJ, Jackson FS, Szekely P. Controlled trial of sotalol for one year after myocardial infarction. Lancet 1982; i: 1142-7.

7 Hampton JR. The use of beta blockers for the reduction of mortality after myocardial infarction. Eur Heart $\mathcal{f}$ 1981; 2: 259-68.

8 Hansteen V, Møinichen E, Lorentsen E, et al. One year's treatment with propranolol after myocardial infarction: preliminary report of Norwegian multicentre trial. $\mathrm{Br}$ Med f 1982; 284: 155-60.

9 Baber NS, Lewis JA. Beta-blockers in the treatment of myocardial infarction [Letter]. $\mathrm{Br} \mathrm{Med} \mathcal{F}$ 1980; 281: 59.

10 May GS, Eberlein KA, Furberg CD, Passamani ER, DeMets DL. Secondary prevention after myocardial infarction: a review of long-term trials. Prog Cardiovasc Dis 1982; 24: 331-52.

11 Baber NS, Evans DW, Howitt G, et al. Multicentre post-infarction trial of propranolol in $\mathbf{4 9}$ hospitals in the United Kingdom, Italy, and Yugoslavia. Br Heart $\mathcal{F}$ 1980; 44: 96-100.

12 Coronary Prevention Research Group. Secondary prevention studies with oxprenolol in coronary heart disease. In: Burley DM, Birdwood GFB, eds. The clinical impact of beta-adrenoceptor blockade. Horsham: Ciba Laboratories, 1980: 165-83.

13 Multicentre International Study. Supplementary report. Reduction in mortality after myocardial infarction with long-term beta-adrenoceptor blockade. $\mathrm{Br} \mathrm{Med} \mathcal{F}$ 1977; ii: $419-21$.

14 Wilhelmsson C, Vedin JA, Wilhelmsen L, Tibblin G, Werkö L. Reduction of sudden deaths after myocardial 
infarction by treatment with alprenolol. Lancet 1974; ii: $1157-60$.

15 Lewis JA. $\beta$-Blockade after myocardial infarction-a statistical view. Br $\mathcal{F}$ Clin Pharmacol 1982; 14, suppl 1: 15S-21S.

16 Andersen MP, Bechsgaard P, Frederiksen J, et al. Effect of alprenolol on mortality among patients with definite or suspected acute myocardial infarction. Preliminary results. Lancet 1979; ii: 865-8.

17 Roland JM, Wilcox RG, Banks DC, Edwards B, Fentem PH, Hampton JR. Effect of beta-blockers on arrhythmias during six weeks after suspected myocardial infarction. Br Med F 1979; ii: 518-21.

18 Lemberg L, Castellanos A Jr, Arcebal AG. The use of propranolol in arrhythmias complicating acute myocardial infarction. Am Heart $\mathcal{F}$ 1970; 80: 479-87.

19 Han J, Garcia de Jalon P, Moe GK. Adrenergic effects on ventricular vulnerability. Circ Res 1964; 14: 516-24.

20 Verrier RL, Thompson PL, Lown B. Ventricular vulnerability during sympathetic stimulation: role of heart rate and blood pressure. Cardiovasc Res 1974; 8: 602-10.

21 Mueller HS, Ayres SM, Religa A, Evans RG. Propranolol in the treatment of acute myocardial infarction. Effect on myocardial oxygenation and hemodynamics. Circulation 1974; 49: 1078-87.

22 Waldenström AP, Hjalmarson AC, Thornell L. A possible role of noradrenaline in the development of myocardial infarction. An experimental study in the isolated rat heart. Am Hean $\mathcal{F}$ 1978; 95: 43-51.

23 Weksler BB, Gillick M, Pink J. Effect of propranolol on platelet function. Blood 1977; 49: 185-96.

24 Campbell WB, Johnson AR, Callahan KS, Graham RM. Anti-platelet activity of beta-adrenergic antagonists: inhibition of thromboxane synthesis and platelet aggregation in patients receiving long-term propranolol treatment. Lancet 1981; ii: $1382-4$.

25 Michelakis AM, McAllister RG. The effect of chronic adrenergic receptor blockade on plasma renin activity in man. $f$ Clin Endocrinol Metab 1972; 34: 386-94.

26 Newman RJ. Comparison of the antilipolytic effect of metoprolol, acebutolol, and propranolol in man. $\mathrm{Br} \mathrm{Med}$ f 1977; ii: 601-3.

27 Grayson J, Irvine M, Parratt JR, Cunningham J. Vasospastic elements in myocardial infarction following coronary occlusion in the dog. Cardiovasc Res 1968; 2: 54-62.

28 Maseri A, L'Abbate A, Baroldi G, et al. Coronary vasospasm as a possible cause of myocardial infarction. $N$ Engl f Med 1978; 299: 1271-7.

29 Parratt JR, Grayson J. Myocardial vascular reactivity after beta-adrenergic blockade. Lancet 1966; i: 338-40.

30 Wolfson S, Gorlin R. Cardiovascular pharmacology of propranolol in man Circulation 1969; 40: 501-11.

31 Wilcox RG, Rowley JM, Hampton JR, Mitchell JRA, Roland JM, Banks DC. Randomised placebo-controlled trial comparing oxprenolol with disopyramide phosphate in immediate treatment of suspected myocardial infarction. Lancet 1980; ii: 765-9.

32 Norris RM, Caughey DE, Scott PJ. Trial of propranolol in acute myocardial infarction. $\mathrm{Br}$ Med $\mathcal{F} 1968$; ii: $398-$ 400.
33 Multicentre trial. Propranolol in acute myocardial infarction. Lancet 1966; ii: 1435-8.

34 Wilcox RG, Roland JM, Banks DC, Hampton JR, Mitchell JRA. Randomised trial comparing propranolol with atenolol in immediate treatment of suspected myocardial infarction. $\mathrm{Br}$ Med $\mathcal{F}$ 1980; 280: 885-8.

35 Balcon R, Jewitt DE, Davies JPH, Oram S. A controlled trial of propranolol in acute myocardial infarction. Lancet 1966; ii: 917-20.

36 Barber JM, Murphy FM, Merrett JD. Clinical trial of propranolol in acute myocardial infarction. Ulster Med $\mathcal{F}$ 1967; 36: 127-30.

37 Barber JM, Boyle DMcC, Chaturvedi NC, Singh N, Walsh MJ. Practolol in acute myocardial infarction. Acta Med Scand [Suppl] 1976; 587: 213-9.

38 Yusuf S, Ramsdale D, Peto R, et al. Early intravenous atenolol treatment in suspected acute myocardial infarction. Lancet 1980; ii: 273-6.

39 Ramsdale DR, Faragher EB, Bennett DH, et al. Ischemic pain relief in patients with acute myocardial infarction by intravenous atenolol. Am Heart $\mathcal{f}$ 1982; 103: 459-67.

40 Shand DG, Rangno RE. The disposition of propranolol. 1) Elimination during oral absorption in man. Pharmacology 1972; 7: 159-68.

41 Alvan G, Bahr C von, Seideman P, Siöqvist F. High plasma concentrations of $\beta$-receptor blocking drugs and deficient debrisoquine hydroxylation [Letter]. Lancet 1982; i: 333.

42 Smith SE. Personal view. Br Med F 1982; 284: 818.

43 Rose G. Prophylaxis with $\beta$-blockers and the community. $\mathrm{Br} \mathcal{F}$ Clin Pharmacol 1982; 14, suppl 1: 45S-8S.

44 Starling MR, Crawford MH, Kennedy GT, O'Rourke RA. Exercise testing early after myocardial infarction: $\overrightarrow{\vec{B}}$ predictive value for subsequent unstable angina and death. Am $\mathcal{F}$ Cardiol 1980; 46: 909-14.

45 Moss AJ, Davis HT, DeCamilla J, Bayer LW. Ventricular ectopic beats and their relation to sudden and nonsudden cardiac death after myocardial infarction. Circulation 1979; 60: 998-1003.

46 Battler A, Karliner JS, Higgins CB, et al. The initial chest $x$-ray in acute myocardial infarction. Prediction of early and late mortality and survival. Circulation 1980; 61: $1004-9$.

47 Sanz G, Castañer A, Betriu A, et al. Determinants of prognosis in survivors of myocardial infarction. $N$ Engl $\mathcal{f}$

Med 1982; 306: 1065-70.
48 Théroux P, Waters DD, Halphen C, Debaisieux JC, 을. Mizgala HF. Prognostic value of exercise testing soon $\mathrm{N}$ after myocardial infarction. $N$ Engl $f$ Med 1979; 301: o 341-5.

49 European Coronary Surgery Study Group. Prospective N randomised study of coronary artery bypass surgery in stable angina pectoris. Second interim report. Lancet 1980; ii: 491-5.

Requests for reprints to Dr D A Chamberlain, $\stackrel{\mathbb{D}}{+}$ Cardiac Department, Royal Sussex County Hospi- $\square$ tal, Brighton BN2 5BE. 